\title{
Effect of Sampling Spacing on the Accuracy of Volume of a Medium-Size Gully
}

\author{
Jun Luo ${ }^{1,2}$, Bin Zhang ${ }^{1,2,3^{*}}$, Du Zhengpin ${ }^{3}$, Zheng Jilin ${ }^{1}$, Liu Hui ${ }^{1,2}$, Qin Fachao ${ }^{1,2}$, \\ Deng Qinchun ${ }^{1,2}$
}

\author{
1 School of Land and Resources, China West Normal University, Nanchong 637009, China \\ 2 Sichuan Provincial Engineering Laboratory of Monitoring and Control for Soil Erosion of Dry Valley, \\ China West Normal University, Nanchong 637009, China \\ 3 Institute of Geographic Sciences and Natural Resources Research, CAS, Beijing 100101, China \\ * Corresponding author's e-mail: envgeo@163.com
}

\begin{abstract}
Accurate morphological parameters are key to understand the process and mechanism of gully erosion, but little information exists regarding the accuracy of gully volume influenced by sampling spacing. In order to assess the influence of sampling spacing on volume of medium gully under the condition of different shapes of gully cross-sections, as well as to provide information for proposed surveys, a MultiStation was utilized to obtain the point cloud of a U- and V-shaped gully. The coordinates were subsequently rarefied to a certain sampling spacing, and the gully volumes of three modes (Mode 1 only including rarefied terrain points; Mode 2 including detailed terrain and rarefied terrain points; Mode 3 including the rarefied detailed terrain points and terrain points with a given sampling spacing) were calculated in ArcGIS. The results showed that the error of gully volume increased non-monotonously with sampling spacing increased, and that the detail points had greater influence on the gully volume of a U-shaped than a V-shaped gully. As to Mode 1 and 2, the relative error $(R E)$ of U-shaped gully volume increased faster with sampling spacing increasing, and presented high positive correlation. However, in the case of a V-shaped gully, a middle positive correlation for Mode 1 can be observed, and the $R E$ was below $3 \%$ for Mode 2 . For Mode 3, an increase in the sampling spacing of the terrain led to the larger $R E$, average $R E$, and variance of absolute error. If extremely high accuracy $(2.5 \%$ of $R E)$ is required, sampling spacing is less than $0.5 \mathrm{~m}$; if high accuracy $(5 \%$ of $R E)$ is set, the sampling spacing of terrain points is below $0.8 \mathrm{~m}$ for a U-shaped gully, while the corresponding sampling spacing of terrain points and detail points are $2.0 \mathrm{~m}$ and $1.85 \mathrm{~m}, 3.0 \mathrm{~m}$ and $1.80 \mathrm{~m}$, and $4.0 \mathrm{~m}$ and $0.75 \mathrm{~m}$ for a V-shaped gully. The shape of the gully's cross-section, as well as the exact location of the shoulder line will affect the accuracy of the gully's volume. This study will increase the efficiency of detail survey in the field for medium gully.
\end{abstract}

Keywords: three modes; sampling spacing; gully volume; shape of gully cross-section

\section{INTRODUCTION}

As an important sediment source in a range of environments (Li et al., 2017; Poesen et al., 2003), gully erosion represents a serious environmental threat around the world. Gullies are common features of mountainous or hilly regions (Valentin et al., 2005), and are defined as deep channels eroded by temporary runoff water, which remove soil from a narrow area to considerable depths (Conoscenti et al., 2014; Poesen, 1993). Gullies comprise one of the few sources of morphological evidence of past intense soil erosion on the landscape, reflecting local environmental changes (Ionita et al., 2015). A permanent gully is a channel ranging from 0.5 to $25-30 \mathrm{~m}$ depth (Poesen et al., 2003). According to the gully classes by FAO (FAO, 1977; Pathak et al., 2006), a permanent gully can be classified as small $(<1 \mathrm{~m})$, medium (1-6 m) and large (>6 m) with gully depth (Deng et al., 2015b). 
Accurate morphological parameters of a gully are important, not only for quantifying soil losses and the rate of gully erosion, but also for understanding their complex dynamics (Castillo et al., 2018; Deng et al., 2015a; Deng et al., 2015b; Nachtergaele and Poesen, 1999; Poesen et al., 2003). Based on cross-sectional morphology, gullies have commonly been recognized as V-shaped and U-shaped according to the cross sections (Deng et al., 2015b). The gully volume shows the contribution of gully erosion in sediment yield (Woodward, 1999), which could be determined by direct field measurements or prediction by empirical relationships and models (Kompani-Zare et al., 2011). Direct field measurement always required more time and budget (Kompani-Zare et al., 2011). Many factors, such as the precision of the survey equipment, the methods of field surveying and data processing, as well as the gully morphology, will affect the accuracy of volume.

Diverse techniques are used to determine gully erosion in field studies (Castillo et al., 2012). The parameters of a gully can be measured either directly or indirectly in the field using instruments, i.e., metric ruler (Bruno et al., 2008), pole (Castillo et al., 2012), tape meter (Frankl et al., 2015), micro-topographic profiler (Avanzi et al., 2018), total station (Caraballo-Arias et al., 2016; Deng et al., 2015a), GPS RTK (Deng et al., 2015a; He et al., 2005), and laser profilemeter (Castillo et al., 2012). In recent years, new technologies such as Unmanned Aerial Vehicles (UAV) (Bazzoffi, 2015; Stocker et al., 2015), structure-from-motion (SFM) (Christian and Davis, 2016), stereoscopic images (Nachtergaele and Poesen, 1999), 3D photo-reconstruction (Gomez-Gutierrez et al., 2014), terrestrial laser scanning (TLS) (Taylor et al., 2018) and light detection and ranging (LiDAR) (Taylor et al., 2018; Wells et al., 2017) have been successfully applied in gully morphology. In terms of the extraction of a digital surface model (DSM), stereoscopic images of SPOT6 and Pleiades PHR1A have higher accuracy than those of ASTER, SRTM and ALOS (Alganci et al., 2018).

Although systematic and random errors can represent issues, topographic coordinates via 3D methods (such as total station, 3D scanning, and photogrammetry) have considerable accuracy, satisfying the needs of gully morphology (Gimenez et al., 2009). At the gully scale, in comparison with 3D photo-reconstruction and LiDAR data techniques, 2D methods (such as laser profilemeter and pole) generate substantial volume error (over 13\%) (Castillo et al., 2012). Relative to gully volume by GPS RTK, the error of a single measurement by tape is approximately $10 \%$ (Yin et al., 2008). The accuracy of the SFM method is very similar to that of TLS (Zhao and Lin, 2016). Taking terrestrial LiDAR as the reference dataset, terrestrial and aerial photogrammetry can perform topographic surveys with considerable efficiency (Wells et al., 2017). At different spatial scales, the accuracy of 3D gully measurements can be influenced in various ways by gully morphology (Castillo et al., 2012; Gimenez et al., 2009). The width of a cross-section of a gully is determined by pixel size of a digital elevation model (DEM), type and size of the channel (Casalí et al., 2015). Photogrammetric techniques for measuring gully volume are strongly affected by the width/depth (W/D) ratio (Gimenez et al., 2009).

Accurate gully volume will help to evaluate the degree of soil erosion. The direct topographic surveys and the reconstructions of DEM are perhaps particularly popular methods to get the gully volume. In terms of gullied areas with dense vegetation, a total station or GPS RTK continues to be used most frequently in 3D coordinate measurement. A more detail characterization of gully morphology can be attained when the sampling spacing of the terrain is smaller, but this requires more time and expense (Castillo et al., 2012). Sampling spacing, also sampling distance, is defined as the distance between two subsequently measured points (a measured horizontal distance), and thus determines the density of the points. The proper sampling spacing will reduce the cost of time and expense with reliable accuracy. Little information is available regarding the accuracy of gully volume influenced by sampling spacing. The objective of this study was to assess the influence of sampling spacing on gully volume under the condition of different shape of gully crosssection. The results will provide information for proposed measurements of sampling spacing for gully volume as the detail survey is inevitable in the field, which will help to obtain improved data under time and economic constraints.

\section{THE STUDY AREA}

The study area is located in Yuanmou Dry-hot Valley in the northern part of the Central Yunnan Plateau, Yunnan Province (SW China) (Fig. 1). 
The soil types in the valley include dry-red soil and vertisol. The vegetation distributed below an altitude of $1,600 \mathrm{~m}$ is mainly shrub savanna, with over $90 \%$ coverage, while forest coverage is approximately 3.4\%-6.3\% (Deng et al., 2015b; Ran et al., 2018). Gully erosion is well developed due to special climate and lower vegetation coverage; it is also a very serious issue that is fragmenting land in the Dry-hot valley. Of the two study sites, Tutuji is a hill near Xiaoleizai village, Huangguayuan, Yuanmou County, with an elevation of 980-1,000 $\mathrm{m}$ above sea level, whereas Shadi is a terrace near the city of Yuanmou at an altitude of 1,040-1,050 m. The permanent gully in Tutuji (at coordinates: 2551'35.6' $\mathrm{N}$, $\left.101^{\circ} 50^{\prime} 05.4^{\prime \prime} \mathrm{E}\right)$, which is about $34.2 \mathrm{~m}$ in length, is a typical V-shape in cross-section with vertisollike materials; whereas the gully (at coordinates: $25^{\circ} 41^{\prime} 30^{\prime \prime} \mathrm{N}, 101^{\circ} 52^{\prime} 21.3^{\prime \prime} \mathrm{E}$ ) with length of about $18.9 \mathrm{~m}$ in Shadi is U-shaped with dry-red soil-like materials. The depth in the gully outlet is $5.3 \mathrm{~m}$ in Shadi and $5.9 \mathrm{~m}$ in Tutuji. Based on gully classification system (FAO, 1977), the two gullies are large ones $(>5 \mathrm{~m})$. Our previous studies show that about 95\% active gullies in the Dry-hot Valley have depth values within 0-6 m (Deng et al., 2015a; Deng et al., 2015b), so the two permanent gullies are very typical in shape of cross section with medium-large size. These two gullied areas are both almost bare and have rough surface (Fig. 1). The average slope gradient of hillslope where the gully located is about $18^{\circ}$ in Tutuji, and $6^{\circ}$ in Shadi.

\section{MATERIALS AND METHODS}

\section{Field data acquisition}

First, in order to obtain accurate terrain data of the gullied area and to mitigate difficulties in post-processing, vegetation was cut off. Subsequently, the layout of control network was made in the gullied area; each control point was surveyed using a Leica Nova MS60 MultiStation. The coordinates were adjusted to be used as a reference

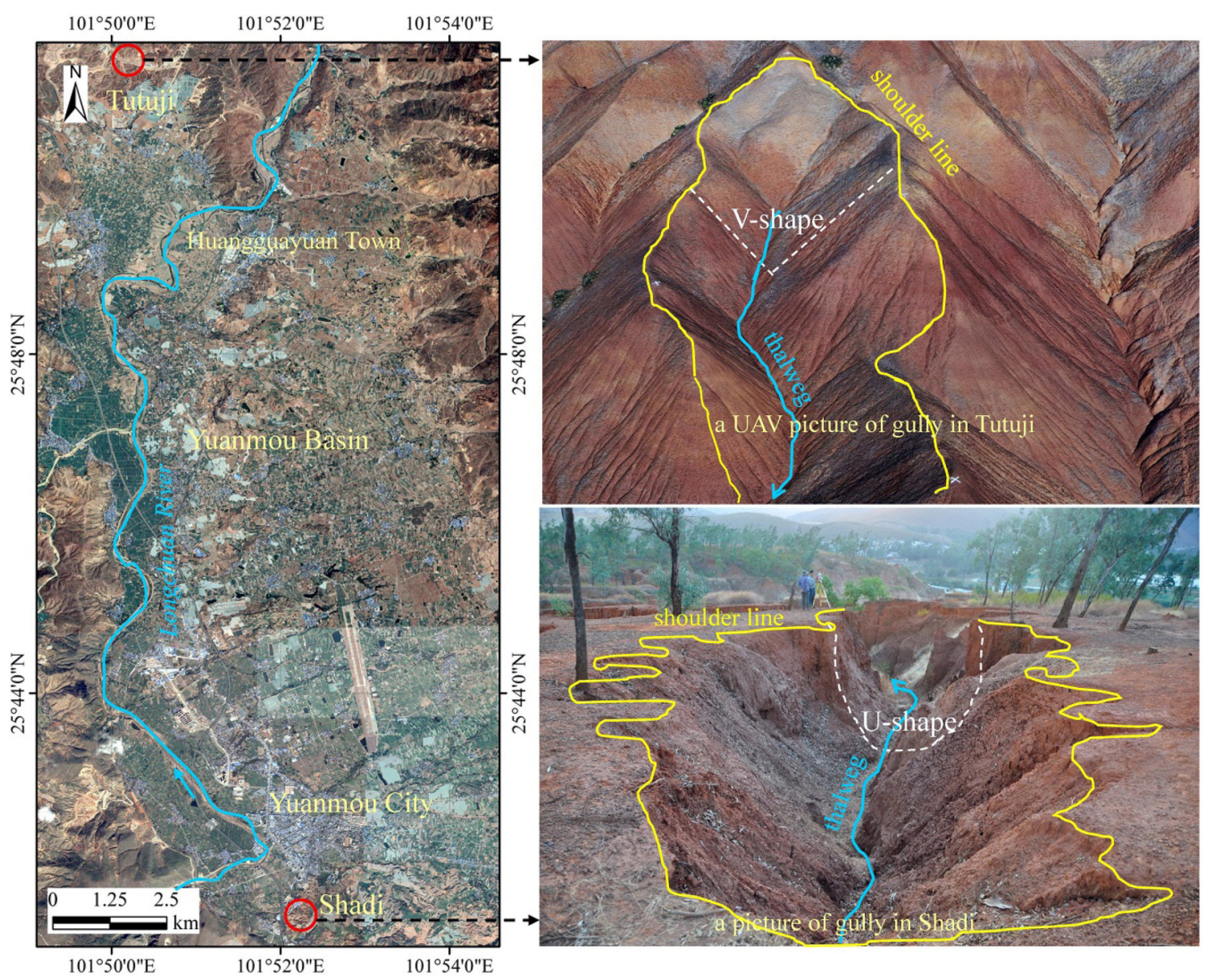

Fig. 1. The study area 
during later scanning. Finally, the terrain in the gullied area was scanned with the MultiStation; multiple scanning was conducted to cover the entire gullied area with a sampling spacing of $1 \mathrm{~cm}$ and accuracy below $2 \mathrm{~mm}$ at a distance of $100 \mathrm{~m}$ from the station point.

\section{Data processing}

\section{Export of the point clouds}

The point clouds scanned in the field were imported into the software of Leica Infinity (version 2.4) (https://leica-geosystems.com/), and the vegetation was filtered by de-noising tool. The data of multi-station scanning were exported as a point cloud data file with .pts format, and the filename extension was subsequently converted to .txt. The former three columns in this text file comprised $\mathrm{X}, \mathrm{Y}, \mathrm{Z}$ coordinates.

\section{Detail points extraction}

The point cloud data (also topological data, TD) were imported and converted as a shapefile of points in ArcGIS software, and a TIN was created and then converted as DEM with a cell size of $1 \mathrm{~cm}$. As to the DEM of the U-shaped gully, contours with a slope of 25 degrees were extracted based on the slope analysis, the maximum length of the contours was the shoulder line (or gully border line), and the thalwegs was extracted using hydrologic analysis. Regarding the DEM of the V-shaped gully, the watershed and stream were extracted using the hydrology tool, and their polylines were regarded as shoulder line and thalwegs.

Using the Buffer tool in ArcGIS, buffer polygons with a width of $10 \mathrm{~cm}$ were generated on both sides of the shoulder lines and thalwegs to form a polygon file characterizing the detail terrain. This polygon was created as an input feature, and the point shapefile was clipped to develop a feature version. The feature shapefile was able to be exported as detail terrain with a txt file format. Thus, two files were in text format: the terrain data (TD) and the detail terrain data (DTD).

\section{Modes and subsampling}

In order to explore accuracy of a gully volume, the data subsampling was used to simulate the field surveys. They were three modes based on permutation and combination of TD or/and DTD rarefied. In each mode, the influence of sampling spacing on gully volume could be simulated by subsampling the coordinates of the TD or/and DTD.

Mode 1: only included the rarefied TD, but the DTD was ignored. In order to discover least coordinate points of terrain surface without considering the detail terrain surface (or characteristic topographies, including the narrow zones that shoulder line and thalwegs located), the terrain surface was surveyed at some sampling spacing. It could be used to represent a case in which the researcher has little surveying knowledge.

Mode 2: included DTD and rarefied TD. The detail terrain surface was focused and surveyed at very small sampling spacing, but the terrain surface was measured with large sampling spacing. In this mode, it attempted to find least coordinate points of terrain surface with ample detail points.

Mode 3: included the rarefied DTD and TD with a given sampling spacing (such as $0.5 \mathrm{~m}$, $1.0 \mathrm{~m}$ or $1.5 \mathrm{~m}$ ). Better combination of less coordinate points of detail terrain surface and detail terrain was explored.

The method of subsampling was as follows. The gullied area was filled with a square of a given side length, the distance between each coordinate and the center of the square was calculated, and the coordinate with minimum distance was saved to form the rarefied data. The given length was equivalent to the sampling spacing, ranging from $0.05 \mathrm{~m}$ to $5.00 \mathrm{~m}$ with an interval of $0.05 \mathrm{~m}$ in this study. The subsampling method was capable of being implemented in MathWorks Matlab (version R2016a).

\section{Volume calculation}

The Cut/Fill Tool in ArcGIS can be used to calculate the gully Volume between two surfaces based on DEM (Wang et al., 2014). The coordinates of a given sampling spacing of each mode were imported into ArcGIS and used to create a DEM with cellsize of $0.05 \mathrm{~m}$. The gully volume was obtained using the Analysis Tools and Spatial Analyst Tools. The shoulder line was extracted by the Slope Tool for the U-shaped gully and by the Hydrology Tool for the V-shaped gully. In order to make the calculation with each sampling spacing easy, the model created with Model Builder in ArcCatalog was able to automatically calculate the gully volume based on coordinate data in text 
format (Fig. 2). Based on slope gradient of the hillslope and multiple tests in this study, slope analysis was performed with a standard value of 25 degrees.

\section{Error calculation}

In order to evaluate the accuracy of a parameter in different conditions, absolute error $(A E)$ and relative error $(R E)$ can be defined as follows:

$$
\begin{gathered}
A E_{j}=p_{j}-p_{0} \\
R E_{j}=\left|\frac{p_{j}-p_{0}}{p_{0}}\right| \times 100 \%
\end{gathered}
$$

where: $j$ indicates a sampling spacing of $j, p_{\mathrm{j}}$ is a value of parameter, $p_{0}$ is a value of parameter calculated by all data without subsampling, thus generating a DEM with cell size $0.01 \mathrm{~m}$.

\section{Correlation coefficient}

The Pearson correlation coefficient is computed to measure the strength of a linear association between the sampling space and $R E$ :

$$
\begin{gathered}
\operatorname{Pearson}(x, y)= \\
=\frac{\sum x y-\frac{\sum x \sum y}{N}}{\sqrt{\left(\sum x^{2}-\frac{\left(\sum x\right)^{2}}{N}\right)\left(\sum y^{2}-\frac{\left(\sum y\right)^{2}}{N}\right)}}
\end{gathered}
$$

where: $(x, y)$ refers to the data objects and $N$ is the total number of attributes. As the coefficient is greater (or less) than 0 , it is positive (or negative) correlation; 0 is no linear correlation.

\section{RESULTS}

\section{U-shaped gully}

Based on TD without subsampling, the gully volume in Shadi was $278.13 \mathrm{~m}^{3}$, as a standard value for the volume of a U-shaped gully.

\section{Mode 1}

When the sampling spacing is below $0.6 \mathrm{~m}$, the volume values are below or above the standard value, the local minimum $A E$ is $-3.66 \mathrm{~m}^{3}$, and the maximum is $11.01 \mathrm{~m}^{3}$. When sampling spacing exceeds $0.6 \mathrm{~m}$, the values of $A E$ are below the standard value (with the exception of $0.92 \mathrm{~m}^{3}$, with sampling spacing of $1.35 \mathrm{~m}$ ), and a downward trend in the variation of gully volume can be identified with the growth of sampling spacing (Fig. 3a). When sampling spacing exceeds $4.0 \mathrm{~m}$, $A E$ occupies over half the standard value. However, when the sampling spacing is below $0.7 \mathrm{~m}$, the $R E$ of the volume of gullies is less than $5 \%$, and $R E$ is less than $10 \%, 15 \%$ and $20 \%$ as sampling spacing does not exceed 1.0, 1.7 and $2.1 \mathrm{~m}$, respectively. Moreover, $R E$ exceeds $50 \%$, while sampling spacing is $3.85 \mathrm{~m}$. In general, increased $R E$ of the gully volume is produced with increased sampling spacing. The Pearson correlation coefficient between the sampling spacing and relative error is 0.87 at the 0.01 level of significance, so the $R E$ of gully volume has a high positive correlation with sampling spacing. The relationship between them can be well fit by exponential model $\left(y=0.03486 \mathrm{e}^{0.6509 x}\right)$ with $95 \%$ confidence bounds, its coefficient of determination $\left(R^{2}\right)$ is 0.86 and RMSE (root-mean-squared error) is 0.096 .

\section{Mode 2}

In terms of Mode 2, the gully volumes fluctuate around the standard value when sampling spacing is below $0.5 \mathrm{~m}$, but only three values can be identified above the standard $\left(3.24 \mathrm{~m}^{3}, 2.28 \mathrm{~m}^{3}\right.$ and $4.45 \mathrm{~m}^{3}$ with sampling spacing of $0.25 \mathrm{~m}$, $0.4 \mathrm{~m}$ and $0.5 \mathrm{~m}$, respectively). The volumes of the gullies are all below the standard value if sampling spacing exceeds $0.5 \mathrm{~m}$ (Fig. 3b). A downward trend in the change in gully volume with increased sampling spacing can be noted. With regard to the relative error, $R E$ does not exceed $5 \%, 10 \%$ and $15 \%$ if sampling spacing is below $0.6,1.45$ and $1.85 \mathrm{~m}$, respectively. Moreover, $R E$ exceeds $20 \%$ while sampling spacing is $2.15 \mathrm{~m}$. In general, the $R E$ of gully volume increases with an increase in sampling spacing. The Pearson correlation coefficient between sampling spacing and $R E$ is 0.94 at the 0.01 level of significance, which show a very high positive correlation. Mode 2 has a higher significance than Mode 1; the detail points reduce the fluctuation of gully volumes and improve the accuracy at the same sampling spacing.

\section{Mode 3}

The error of gully volume is evaluated based on the terrain and rarefied detail points, which require the sampling spacing of terrain points to be 

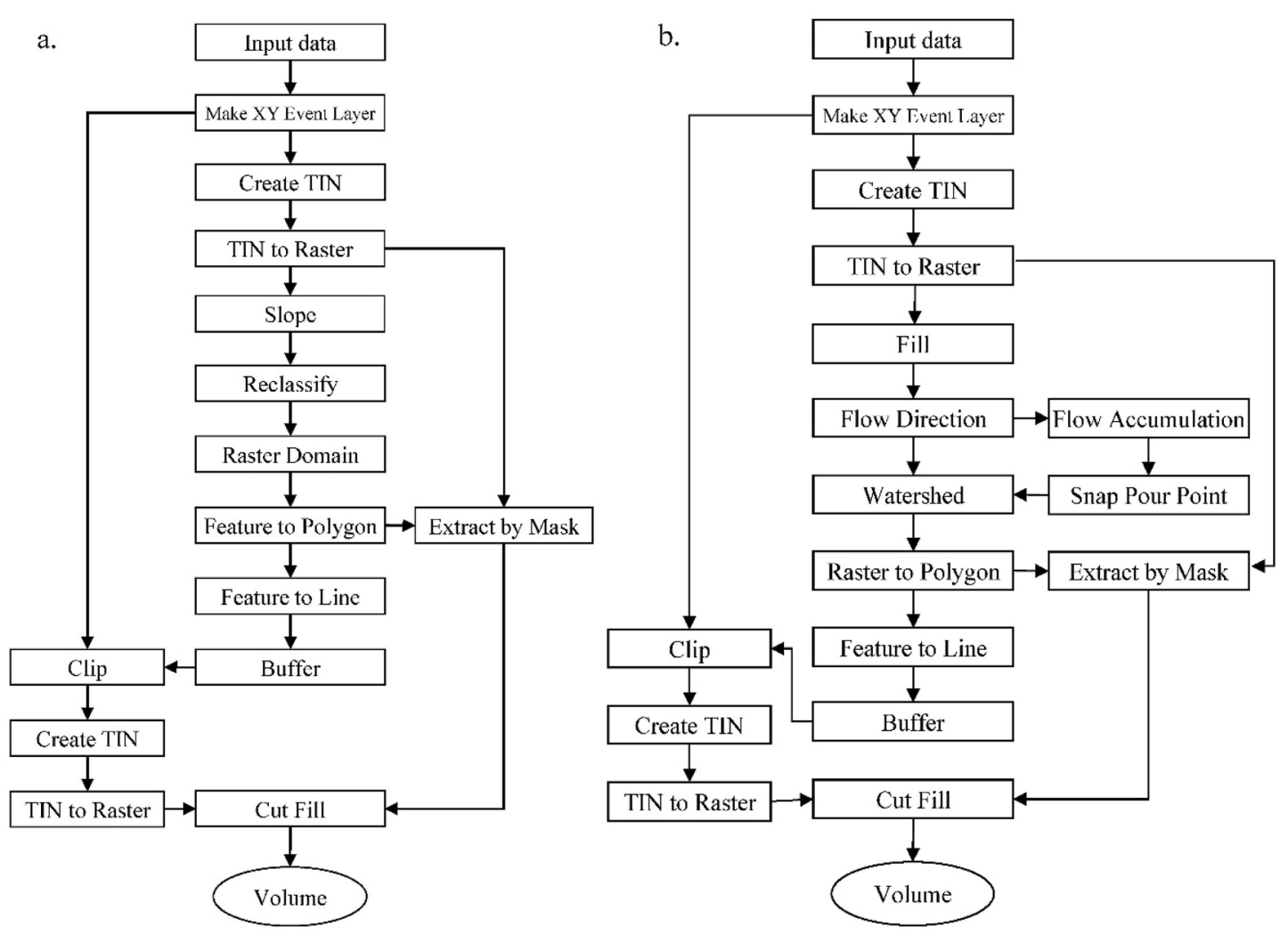

Fig. 2. The procedure to calculate the gully volume in ArcGIS: a) U-shaped gully; b) V-shaped gully

$0.5,1.0,1.5$ and $2.0 \mathrm{~m}$, respectively. When the sampling spacing of terrain points is $0.5 \mathrm{~m}$, the gully volumes exceed the standard value in different conditions of detail points (Fig. 3c), and $A E$ does not exceed $12 \mathrm{~m}^{3}$. Moreover, $R E$ shows an increasing trend as the sampling spacing of detail points increases, but the maximum value of $R E$ is less than $5 \%$, indicating that the density of the detail points has little influence on the accuracy of volume values while the terrain points have a relatively high density (sampling spacing is $0.5 \mathrm{~m}$ ).

When the sampling spacing of terrain points is $1.0,1.5$ and $2.0 \mathrm{~m}$ respectively, the volumes are all below the standard value in different rarefied detail points (Fig. 3d-f). Fluctuations in gully volume are extremely high in three different conditions, indicating a non-significant downward trend in different rarefied detail points as the sampling spacing of terrain coordinates increases. The distribution ranges of the $A E$ are -35.53 to $-21.78 \mathrm{~m}^{3},-45.50$ to $-20.27 \mathrm{~m}^{3}$ and -57.83 to $-24.93 \mathrm{~m}^{3}$, the average values of $A E$ are $-28.05 \mathrm{~m}^{3}$, $-34.63 \mathrm{~m}^{3}$ and $-43.30 \mathrm{~m}^{3}$, and the variances are 7.30, 22.08 and 27.97, respectively. This suggests that with the increase of sampling spacing of terrain points, the average values of $A E$ tend to be large and their distribution discrete. The $R E$ of gully volume ranges from 7.83 to $12.78 \%, 7.29$ to $22.08 \%$ and 8.96 to $20.79 \%$ under the three conditions, and the averages are $10.08 \%, 12.15 \%$ and $15.57 \%$, respectively. The probability distribution (Fig. 4) clearly indicates that the $R E$ of the gully volume significantly increases when the sampling spacing of terrain points increases.

\section{V-shaped gully}

Given that the gully head in Tutuji obviously contains two tributaries, a section of the main gully is considered for the convenience of study. The volume value of $1,923.34 \mathrm{~m}^{3}$ is used as standard, obtained according to the scanning coordinate data.

\section{Mode 1}

In Fig.5a, a relatively large difference is evident in the gully volume between different sampling spacings, with 27 values above the standard and 73 values below the standard. When sampling spacing is below $1.20 \mathrm{~m}$, the values of $A E$ of the gully volumes are basically distributed in a range from -55 to $55 \mathrm{~m}^{3}$ (the value slightly exceeds the range only when sampling spacing equals $0.80 \mathrm{~m}$ ). The variation of $A E$ becomes 

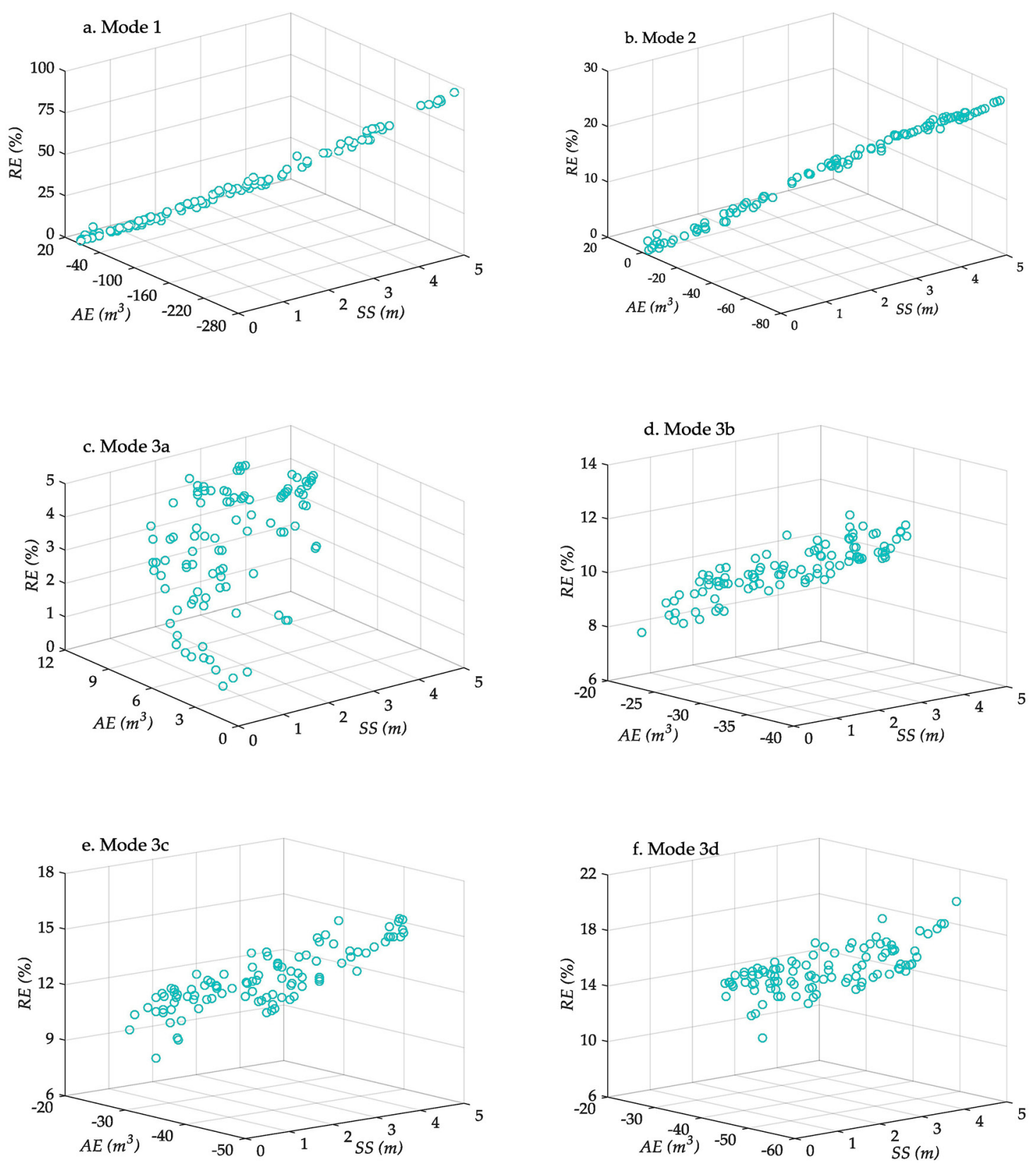

Fig. 3. $R E$ and $A E$ of a U-shaped gully

significant: $A E$ reaches a value of $-124.35 \mathrm{~m}^{3}$ and $107.73 \mathrm{~m}^{3}$ when sampling spacing equals 1.35 and $1.50 \mathrm{~m}$, respectively. In addition, $A E$ significantly deviates from the standard value as sampling spacing equals $2.25 \mathrm{~m}$, and $A E$ approaches $-1,088.85 \mathrm{~m}^{3}$ when sampling spacing equals $4.75 \mathrm{~m}$. The average and variance of $A E$ are $-111.28 \mathrm{~m}^{3}$ and $4,8971.58$, respectively, indicating that the distribution of volume values is extremely discrete. The $R E$ of the gully volume demonstrates considerable volatility as sampling spacing changes. $R E$ does not exceed 5\% when sampling spacing is less than $1.30 \mathrm{~m}$; moreover, the maximum $R E$ does not exceed $10 \%, 15 \%$ or $20 \%$ when sampling spacing is below $2.20,2.95$ and $3.60 \mathrm{~m}$, respectively. However, $R E$ can reach a value of $56.61 \%$ if sampling spacing exceeds $4.0 \mathrm{~m}$. The Pearson correlation coefficient is 0.57 , showing a middle positive correlation between $R E$ of gully volume and sampling spacing.

\section{Mode 2}

When sampling spacing is less than $0.6 \mathrm{~m}$, the range of gully volume which above or below the standard value is very close. The gully volumes 


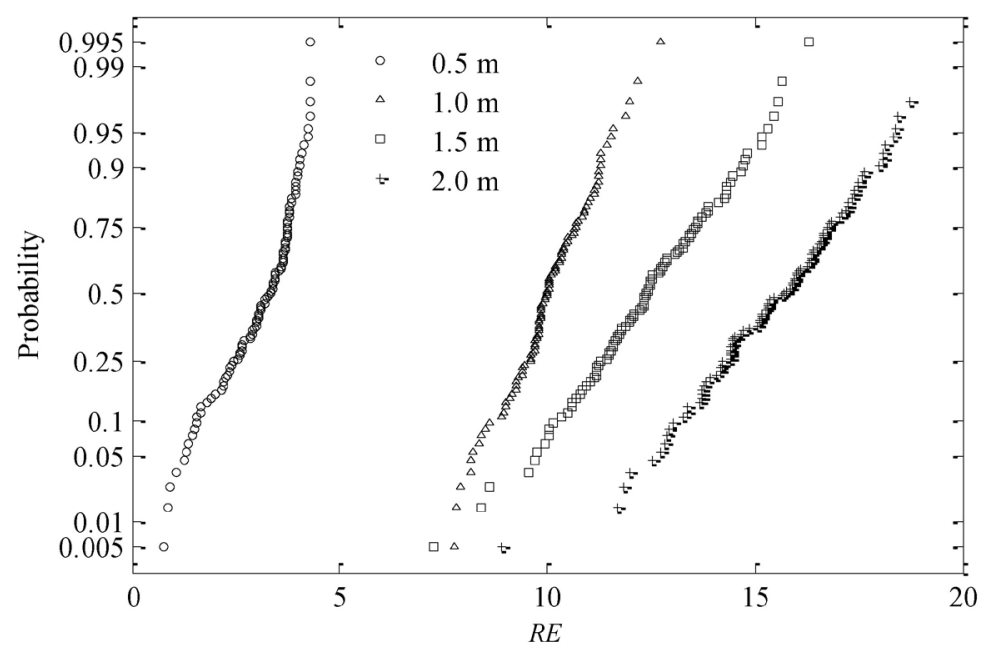

Fig. 4. The probability distribution of relative error in the case of Mode 3

are less than the standard value if sampling spacing ranges from 0.6 to $2.8 \mathrm{~m}$, while they are larger when sampling spacing is greater than $2.8 \mathrm{~m}$ (Fig. 5b). Regarding the variation of $A E$, the values are approximately distributed in the range of -30 to $50 \mathrm{~m}^{3}$. When sampling spacing is less than $1.0 \mathrm{~m}, A E$ has a relatively large range, and the minimum and maximum are $-26.69 \mathrm{~m}^{3}$ (when sampling spacing is $0.3 \mathrm{~m}$ ) and $42.87 \mathrm{~m}^{3}$, respectively. However, $A E$ is almost negative when sampling spacing ranges from 1.00 to $3.00 \mathrm{~m}$, and the minimum of $A E$ is $-29.78 \mathrm{~m}^{3}$; except for the sampling spacing of $4.10 \mathrm{~m}, A E$ is positive when sampling spacing is greater than $3.0 \mathrm{~m}$, the maximum is $49.72 \mathrm{~m}^{3}$. The $R E$ of gully volume slightly fluctuates as sampling spacing changes: the maximums are less than $2.59 \%$, which indicates that no matter how sampling spacing changes, the $R E$ of volume is relatively small under the condition of a high-density point. The result indicates that the volume of a V-shaped gully is almost determined by the detail points; in other words, it is largely decided by the coordinates of the shoulder line and the bottom line (thalweg) of the gully.

\section{Mode 3}

When the sampling spacing of terrain points is $0.5 \mathrm{~m}$ and the sampling spacing of detail terrain points varies from 0.05 to $5.00 \mathrm{~m}$, the $A E$ of gully volume ranges from -44.20 to $43.80 \mathrm{~m}^{3}$, with a maximum $R E$ value of $2.30 \%$ (Fig. $5 \mathrm{c}$ ). When the sampling spacing of terrain points is $1.0 \mathrm{~m}$, the variation of gully volume tends to be large, with $R E$ displaying a maximum value of $5.0 \%$ (Fig. 5d). However, if sampling spacing is $1.50 \mathrm{~m}$
(Fig. 5e), most gully volumes are below the standard value, especially when sampling spacing is small. Meanwhile, $R E$ presents an irregular volatility when the sampling spacing of detail points changes, with a maximum value of $9.43 \%$. With the increase in the sampling spacing of terrain points, higher volatility results, and $R E$ is below $5 \%$ when sampling spacing is less than $2.0 \mathrm{~m}$.

If the sampling spacing of terrain points is $2.0 \mathrm{~m}, 3.0 \mathrm{~m}, 4.0 \mathrm{~m}$, or $5.0 \mathrm{~m}$, the $R E$ of gully volume is $8.83 \%, 15.27 \%, 17.17 \%$, and $16.60 \%$ respectively (Fig. 5f-i). The gully volumes are almost less than the standard and present high volatility. In particular, stronger fluctuation is obvious when the sampling spacing of detail terrain is above $2.0 \mathrm{~m}$. In this case, the $R E$ of the volume does not exceed $5 \%$ if the sampling spacing of detail points is less than $2.0 \mathrm{~m}$, but $R E$ increases and strongly fluctuates if it is over $2.0 \mathrm{~m}$. When the sampling spacing of terrain points is $0.5 \mathrm{~m}, 1.0 \mathrm{~m}, 1.5 \mathrm{~m}, 2.0 \mathrm{~m}, 3.0 \mathrm{~m}, 4.0 \mathrm{~m}$, and $5.0 \mathrm{~m}$, the variances of absolute volume error are $344.68,772.95,2,721.11,3,177.0,5,575.21$, $10,850.82$ and $12,263.04$, and the average $R E$ is $0.76 \%, 1.57 \%, 2.13 \%, 2.70 \%, 3.29 \%, 3.76 \%$, and $4.04 \%$, respectively. This indicates that the variances and average values increase simultaneously with sampling spacing.

\section{DISCUSSIONS}

How long is the appropriate sampling spacing? Although the widespread application of 3D laser scanner and photogrammetric technology has increased the feasibility of attaining accurate 

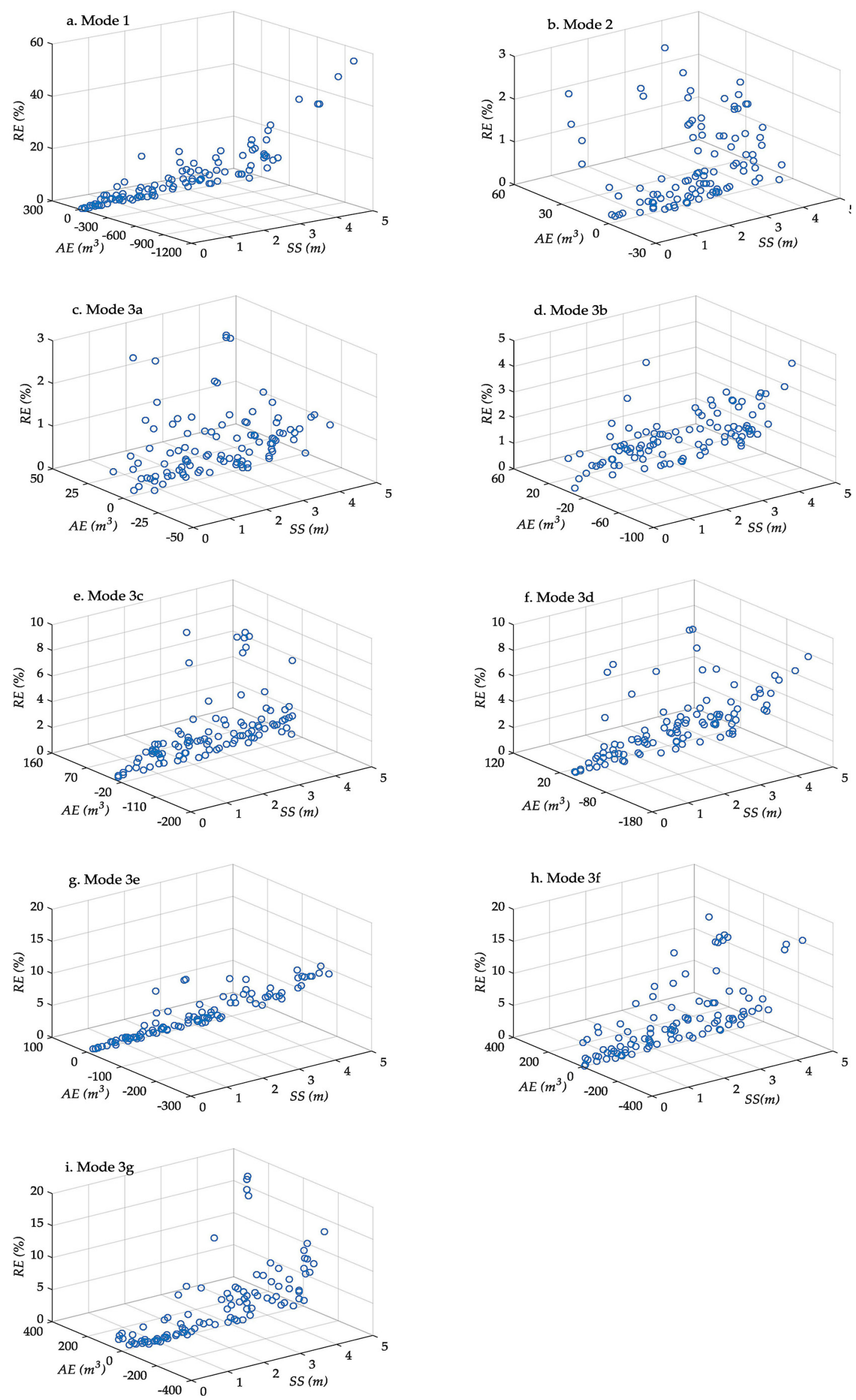

Fig. 5. $R E$ and $A E$ of a $\mathrm{V}$-shaped gully 
point cloud data with a high density, the highly dense vegetation present in gullied area is likely to make effective terrain data acquisition very difficult. Thus, the total station and differential GPS are commonly used to acquire terrain data. Although GPS can provide 3D positions in any weather condition, obstructions (such as trees and tall shrubs) that block the line of sight between the satellite and the antenna make it impossible to utilize, and so the total station must be considered as the ideal choice. Moreover, sampling spacing should be carefully considered amongst these measurement techniques no matter the shape of the gully. Indeed, whether U- or V-shaped, the $R E$ are less than $2.5 \%$ when sampling spacing does not exceed $0.5 \mathrm{~m}$ (Fig. 6). The sampling spacing of $0.5 \mathrm{~m}$ far exceeds the crack width on the surface of a gullied area, and also sufficiently reflects micro-topographic changes. Therefore, Mode 1 is suitable for a researcher with no knowledge of surveying. However, whilst this mode offers a very high level of accuracy, fieldwork is extremely strenuous. Mode 2 is appropriate for a researcher with some knowledge of surveying but who lacks experience; sampling spacing for U-shaped gullies should not exceed $0.6 \mathrm{~m}$, and $1.25 \mathrm{~m}$ for V-shaped gullies, if RE of less than $5 \%$ is required. Furthermore, if a precision level of $10 \%$ is required, sampling spacing should not exceed $1.15 \mathrm{~m}$ or $2.1 \mathrm{~m}$ for U-shaped and V-shaped gullies, respectively. For larger gullies, this method would cost less time than Mode 1.

Mode 3 is appropriate for a researcher with professional experience. It considers both the sampling spacing of terrain and detail terrain; the latter should be less than the former. For U-shaped gullies, regardless of the sampling spacing of detail terrain, the maximum $R E$ is $4.25 \%$ only if the sampling spacing of the terrain points is $0.5 \mathrm{~m}$, but

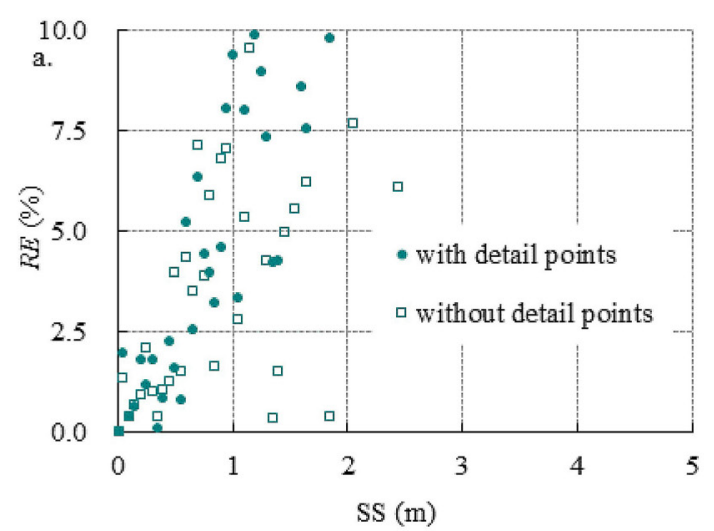

if the sampling spacing of terrain exceeds $1.0 \mathrm{~m}$, an $R E$ of less than $5 \%$ cannot be guaranteed. This is because the minimum $R E$ is greater than $7 \%$ irrespective of the sampling spacing of detail terrain. For $\mathrm{V}$-shaped gullies, the maximum $R E$ is $2.3 \%$ if the sampling spacing of terrain points is 0.5 ; the maximum $R E$ become $5 \%$ if the latter is $1.0 \mathrm{~m}$, but for the detail terrain it is $3.8 \mathrm{~m}$ when the $R E$ is $5 \%$, which is meaningless. Therefore, the sampling spacing of terrain can be increased and that of the detail terrain can be reduced. Consequently, according to Mode 2, sampling spacing of detail points is $1.30 \mathrm{~m}$. While the combinations of sampling spacing of TD and DTD are $2.0 \mathrm{~m}$ and $1.85 \mathrm{~m}, 3.0 \mathrm{~m}$ and $1.80 \mathrm{~m}$, and $4.0 \mathrm{~m}$ and $0.75 \mathrm{~m}$, and can help to ensure the $R E$ of the volume of the V-shaped gully remains below $5 \%$. For a U-shaped gully, $R E$ could reach $10 \%$ when the sampling spacing of TD and DTD are both $1.0 \mathrm{~m}$, while an $R E$ of $10 \%$ cannot be guaranteed if the sampling spacing is above $1.5 \mathrm{~m}$. However, for a V-shaped gully, an $R E$ of less than $10 \%$ can be guaranteed as long as the sampling spacing of terrain points is less than $2.0 \mathrm{~m}$, and the sampling spacing of 3.0 and $4.0 \mathrm{~m}$ of TD correspond to 2.35 and $2.75 \mathrm{~m}$ of DTD, respectively.

\section{Factors influencing the accuracy of gully volume}

In order to calculated gully volumes, the position of the shoulder line should be located with considerable accuracy. In the case of a U-shaped gully, the transition from hillslope to gullied area is obvious, which should be presented as a curve (shoulder line) in 3D space. However, it cannot be precisely identified in the field because it is usually shown as a narrow belt. The difference in the shoulder line as a result of a shift in individual

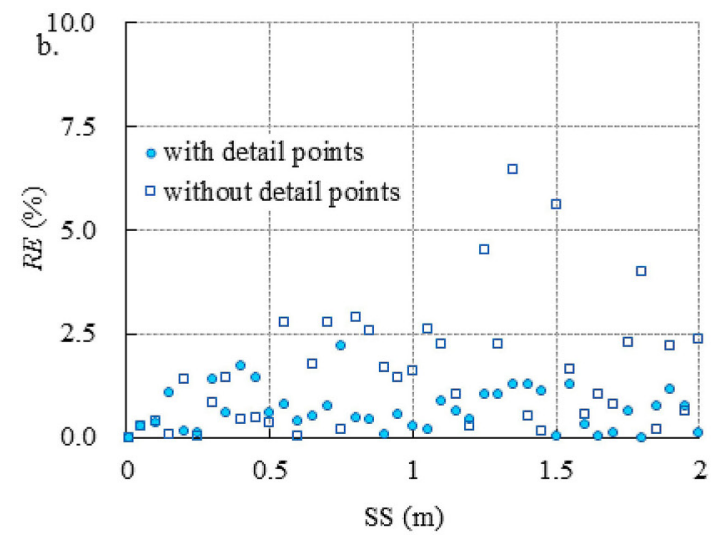

Fig. 6. Relation matrices of $R E$ and sampling spacing. a. U-shaped gully; b. V-shaped gully 
judgment will lead to a deviation in the gully volume recorded. The slope value in this belt demonstrates a trend of increasing from the slope to the gully, hence a value might be determined as the threshold of the shoulder line, which can be achieved via Slope analysis in ArcGIS. However, a different shoulder line calculated from a different slope threshold would certainly result in a difference in volume. In this study, a given value could be obtained due to the small change of the slope of hill surface; it is very difficult to determine whether the slope greatly undulates, and the shoulder line is proposed for measurement in the field in such a situation. In this study, the slope as a threshold was $25^{\circ}$, but the way in which the threshold influences gully volume as changes must be investigated in the future. For a V-shaped gully, the boundary of the watershed could represent the shoulder line if the catchment area is equivalent to the gully area, which could be extracted via Hydrological analysis in ArcGIS. Otherwise, it can only be recognized and measured in the field.

As to a permanent gully, the precision of coordinates by total station or GPS RTK can satisfy the calculation of gully volume. The accuracy of gully volume is not only affected by the density of coordinates, but also by the morphology of gullies. The results in this study indicate that the sensitivity of gully volume to cross-sectional shape is different: the U-shaped gully is more sensitive. Accuracy is also affected by the size of gully and the degree of curvature in plane form. The proposed sampling spacing will diminish if the gully size (such as the width and depth) is relatively smaller and the curvature greater, or increase if larger and straighter. In the case of a complex gully, the sampling spacing should be approximately $10 \%$ shorter than the threshold (Pesci et al., 2011). To establish an empirical model between the gully size and the proper sampling spacing is necessary in future studies. According to gully depth, FAO classified a gully as small $(<1 \mathrm{~m})$, medium (1-5 m) and large ( $>5 \mathrm{~m})$ (FAO, 1977; Pathak et al., 2006). The depth of two gullies in this study is slightly higher than the threshold of large gully, so the proposed sampling space is fit for the medium and medium-large gully. In addition, most gullies are less in depth than those in this study based on our previous works (Deng et al., 2015b), so the result will be helpful to active gully surveys in the Dry-hot Valley.

\section{Uncertainties in gully volume}

In this study, the variation of the $R E$ of gully volume demonstrated volatile and nonlinear characteristics, indicating that $R E$ does not always increase or decrease monotonically as sampling spacing varies. Given that the accuracy of a certain value of sampling spacing is relatively poor, it is plausible that the adjacent sampling spacing's accuracy is superior. The fluctuation of gully volume indicates that the gully's surface is rugged due to soil erosion and cracks, and that its volume is not exactly accurate with more intensive point clouds, hence the locations of coordinates (especially when these are not overly intensive) are very important to the micro-topography of the gully. Furthermore, the gully volume demonstrates very little fluctuation where the sampling spacing changes only slightly in the case of highly intensive coordinates of terrain. It leads to uncertainties in gully volume through field measurements. The real value of gully volume, as a standard value, exists in theory but cannot be practically measured using discrete coordinates. Highly intensive point clouds can help to approach the real value, but not become equal. However, a very small difference between the two makes no sense for a permanent gully or a large gully, and can be ignored in practice. Based on intensive point clouds by multiple stations, the standard value of gully volume is reliable in this study.

\section{CONCLUSIONS}

There exists nonlinear relationship between sampling spacing and gully volume. With the increase of sampling spacing, gully volume error will fluctuate in local interval but follow an overall upward trend, which shows a complex surface of gullies area (such as rough and sinuous). The shape of a gully's cross-section has a significant effect on volume accuracy. In this study, the volume of a U-shaped gully is more dependent on detail points than that of a V-shaped gully. As to Modes 1 (without detail terrain points) and 2 (with detail points), the $R E$ of a U-shaped gully presents a significant functional dependence with sampling spacing; whereas the V-shaped gully doesn't demonstrate a significant functional relationship. In terms of Mode 3 (with terrain points and detail points), the increase in sampling spacing of terrain points will result in large $R E$ values, 
$A E$ variance and average $R E$. For accurate gully volume with detail survey, appropriate sampling spacing should be derived from the gully shape. If the sampling spacing is less than $0.5 \mathrm{~m}, R E$ will not exceed $2.5 \%$ regardless of whether the medium gully is $\mathrm{U}$-shaped or $\mathrm{V}$-shaped. If the $R E$ is set as no more than $5 \%$ under the condition of high accuracy, the sampling spacing of terrain points will be less than $0.8 \mathrm{~m}$ in a U-shaped gully; the corresponding sampling spacings of terrain points and detail terrain points in a V-shaped gully are $2.0 \mathrm{~m}$ and $1.85 \mathrm{~m}, 3.0 \mathrm{~m}$ and $1.80 \mathrm{~m}, 4.0 \mathrm{~m}$ and $0.75 \mathrm{~m}$. This specific dataset is suitable for gully with medium-size. The results will contribute to effective field investigations and precise characterizations of gully volume.

\section{Acknowledgements}

This study was supported by National Natural Science Foundation of China (41971015, 41421001), the Innovation Project of LREIS (O88RA600YA), the Project of Science \& Technology Department of Sichuan Province (2018SZ0337, 2018JY0318, 2017JY0189), the Project of Sichuan Provincial Department of Education (18TD0025, 18ZA0465, 16ZB0182), the Meritocracy Research Funds of China West Normal University (17YC134, 17YC122), and the Fundamental Research Funds of China West Normal University (16A001,17C032).

\section{REFERENCES}

1. Alganci, U., Besol, B., Sertel, E. 2018. Accuracy Assessment of Different Digital Surface Models. Isprs International Journal of Geo-Information, 7, $1-16$.

2. Avanzi, F. et al. 2018. Centimetric Accuracy in Snow Depth Using Unmanned Aerial System Photogrammetry and a MultiStation. Remote Sensing, 10,765 .

3. Bazzoffi, P. 2015. Measurement of rill erosion through a new UAV-GIS methodology. Italian Journal of Agronomy, 10, 18.

4. Bruno, C., Di Stefano, C., Ferro, V. 2008. Field investigation on rilling in the experimental Sparacia area, South Italy. Earth Surface Processes and Landforms, 33, 263-279.

5. Caraballo-Arias, N.A., Conoscenti, C., Di Stefano, C., Ferro, V., Gomez-Gutierrez, A. 2016. Morphometric and hydraulic geometry assessment of a gully in SW Spain. Geomorphology, 274, 143-151.
6. Casalí, J., Giménez, R., Campobescós, M.A. 2015. Gully geometry: what are we measuring? Soil, 1, 509-513.

7. Castillo, C., Marín-Moreno, V.J., Pérez, R., MuñozSalinas, R., Taguas, E.V. 2018. Accurate automated assessment of gully cross-section geometry using the photogrammetric interface FreeXSapp. Earth Surface Processes and Landforms, 43, 1726-1736.

8. Castillo, C. et al. 2012. Comparing the Accuracy of Several Field Methods for Measuring Gully Erosion. Soil Science Society of America Journal, 76, 1319-1332.

9. Christian, P., Davis, J. 2016. Hillslope gully photogeomorphology using structure-from-motion. Zeitschrift Fur Geomorphologie, 60, 59-78.

10. Conoscenti, C. et al. 2014. Gully erosion susceptibility assessment by means of GIS-based logistic regression: A case of Sicily (Italy). Geomorphology, 204, 399-411.

11. Deng, Q. et al. 2015a. Planar morphology and controlling factors of the gullies in the Yuanmou Dryhot Valley based on field investigation. Journal of Arid Land, 7, 778-793.

12. Deng, Q. et al. 2015b. Characterizing the morphology of gully cross-sections based on PCA: A case of Yuanmou Dry-Hot Valley. Geomorphology, 228, 703-713.

13. FAO, 1977. Guidelines for watershed management in: FAO (Ed.), FAO Conservation Guide FAO, Rome (Italy), pp. 293.

14. Frankl, A. et al. 2015. Detailed recording of gully morphology in 3D through image-based modelling. Catena, 127, 92-101.

15. Gimenez, R. et al. 2009. Accuracy of high-resolution photogrammetric measurements of gullies with contrasting morphology. Earth Surface Processes and Landforms, 34, 1915-1926.

16. Gomez-Gutierrez, A., Schnabel, S., BerenguerSempere, F., Lavado-Contador, F., Rubio-Delgado, J. 2014. Using 3D photo-reconstruction methods to estimate gully headcut erosion. Catena, 120, 91-101.

17. He, F., Li, Y., Li, L., Zhang, Q., Bai, L. 2005. Assessing Gully Development in Upper Yangtze River Basin Based on GPS and GIS. Journal of Soil and Water Conservation, 19, 19-22.

18. Ionita, I., Fullen, M.A., Zglobicki, W., Poesen, J. 2015. Gully erosion as a natural and human-induced hazard. Natural Hazards, 79, S1-S5.

19. Kompani-Zare, M., Soufi, M., Hamzehzarghani, H., Dehghani, M. 2011. The effect of some watershed, soil characteristics and morphometric factors on the relationship between the gully volume and length in Fars Province, Iran. CATENA, 86, 150-159. 
20. Li, Z. et al., 2017. A gully erosion assessment model for the Chinese Loess Plateau based on changes in gully length and area. Catena, 148, 195-203.

21. Nachtergaele, J., Poesen, J. 1999. Assessment of soil losses by ephemeral gully erosion using highaltitude (stereo) aerial photographs. Earth Surface Processes and Landforms, 24, 693-706.

22. Pathak, P., Wani, S.P., Sudi, R. 2006. Gully Control in SAT Watersheds. Journal of Sat Agricultural Research, 2, 1-22.

23. Pesci, A., Teza, G., Bonali, E. 2011. Terrestrial Laser Scanner Resolution: Numerical Simulations and Experiments on Spatial Sampling Optimization. Remote Sensing, 3, 167.

24. Poesen, J. 1993. Gully typology and gully control measures in the European loess belt. Elsevier Science Publishers B.V.

25. Poesen, J., Nachtergaele, J., Verstraeten, G., Valentin, C. 2003. Gully erosion and environmental change: importance and research needs. Catena, 50, 91-133.

26. Ran, H. et al. 2018. Morphology and influencing factors of rills in the steep slope in Yuanmou DryHot Valley (SW China). Catena, 165, 54-62.

27. Stocker, C., Eltner, A., Karrasch, P. 2015. Measuring gullies by synergetic application of UAV and close range photogrammetry - A case study from Andalusia, Spain. Catena, 132, 1-11.

28. Taylor, R.J. et al. 2018. Quantifying sediment connectivity in an actively eroding gully complex, Waipaoa catchment, New Zealand. Geomorphology, 307, 24-37.

29. Valentin, C., Poesen, J., Li, Y. 2005. Gully erosion: Impacts, factors and control. Catena, 63, 132-153.

30. Wang, T. et al. 2014. A Quantitative Study of Gully Erosion Based on Object-Oriented Analysis Techniques: A Case Study in Beiyanzikou Catchment of Qixia, Shandong, China. The Scientific World Journal, 2014, 1-11.

31. Wells, R.R., Momm, H.G., Castillo, C. 2017. Quantifying uncertainty in high-resolution remotely sensed topographic surveys for ephemeral gully channel monitoring. Earth Surface Dynamics, 5, 347-367.

32. Woodward, D.E. 1999. Method to predict cropland ephemeral gully erosion. CATENA, 37, 393-399.

33. Yin, J., Wu, Y., Wang, Y. 2008. Error Analysis of Gullies' Measurement with Different Methods. Research of Soil and Water Conservation, 15, 12-16.

34. Zhao, W., Lin, Z. 2016. SFM precise surface measurement: evaluation of resolution and accuracy and error analysis. Geography and Geo-information Science, 23, 25-31. 